\title{
Prevalence of Odontogenic Cysts and Tumors - A Clinicopathological Study
}

\author{
Sushruth Nayak ${ }^{1}$, Asha Karadwal ${ }^{2}$, Prachi Nayak ${ }^{3}$, Kush Pathak ${ }^{3}$ \\ ${ }^{1}$ Professor \& Head, ${ }^{2}$ Sr. Lecturer, ${ }^{3}$ Reader, Department of Oral Pathology \& Microbiology, M.M. College of Dental \\ Sciences And Research, M.M (Deemed to be University), Mullana (Ambala), Haryana
}

\begin{abstract}
Background: The incidence and frequency of odontogenic cysts and tumors depends on the different geographic location. Odontogenic cysts and tumors are lesions that arise from the tooth apparatus or its remnants. The purpose of this study was to determine the prevalence of odontogenic cysts and tumors over a period of 5 years 9 months and to compare our results with other published studies.
\end{abstract}

Aim and Objective: The purpose of this study was to evaluate the prevalence of odontogenic cysts and tumors diagnosed at the Department of Oral Pathology, M.M. College of Dental Sciences \& Research, Mullana (Ambala) and to compare the results with findings in the literature.

Materials and Method: Data of odontogenic cysts and tumors diagnosed during 2014 to 2019 (till September) w4ere collected from the files of the Oral Pathology Department, M.M. College of Dental Sciences \& Research, Mullana (Ambala).

Results: Out of the total 71 cases of odontogenic cysts, most prevalent odontogenic cysts were found to be radicular cysts $(n=42, \%=59.1 \%)$, followed by dentigerous cysts $(n=17, \%=23.9 \%)$ and odontogenic keratocyst $(n=12, \%=16.9 \%)$. Among the odontogenic tumors out of 49 cases reported, the most prevalent was ameloblastoma $(n=28, \%=57.1 \%)$ followed by, ameloblastic fibroma $(n=06, \%=12.2 \%)$, odontoma $(\mathrm{n}=05, \%=10.2 \%)$, adenomatoid odontogenic tumor $(\mathrm{n}=03, \%=6.1 \%)$, peripheral odontogenic fibroma $(\mathrm{n}=02, \%=4.08 \%)$, ameloblastic carcinoma $(\mathrm{n}=02, \%=4.08 \%)$, odontogenic fibroma $(\mathrm{n}=02, \%=4.08 \%)$ and odontogenic myxofibroma $(\mathrm{n}=01, \%=2.04 \%)$. The anterior and posterior portion of the body of mandible was the most common site for both odontogenic cysts and tumors. The age group for odontogenic cysts ranged from 07 to 72 years of age, whereas for the odontogenic cysts the range was 10 to 75 years of age. The male to female ratio for the odontogenic cysts was 1:1.2, whereas for the odontogenic tumors it was found to be having more female predilection with the ratio of $1: 1.3$.

Conclusion: The prevalence of odontogenic cysts was similar to that reported in the literature, with incidence of radicular cysts seen most frequently. In case of odontogenic tumors the findings vary to the reported literature with ameloblastoma being more commonly reported.

Key words: Ameloblastoma, dentigerous cysts, odontogenic cyst, odontogenic tumors, odontoma, radicular cysts

\section{Introduction}

Odontogenic cysts and tumors are derived from epithelial, ectomesenchymal or both the elements of the tooth-forming apparatus. ${ }^{1,2}$ The jaws are host to a wide variety of cysts and tumors because large part of the tissue is involved in tooth formation. ${ }^{3}$ These generally show slow, expansive growth and in some cases associated with marked bone destruction and recurrence. ${ }^{4}$ Studies using histopathological data are important to characterize and establish the prevalence of oral and maxillofacial lesions in different age groups. In this respect, research based biopsy records are necessary to analyse the main types of lesions that occur in a given population and to provide data that can guide pathologists particularly in the 
diagnosis and management of these lesions. Therefore, the purpose of this study was to evaluate the prevalence of different types of odontogenic cysts and tumors diagnosed histopathologically over a period of 5 years and 09 months in Mullana (Ambala) at the institutional level according to age, gender and site affected and to compare the results with findings in the literature.

\section{Materials and Method}

Data of odontogenic cysts and tumors diagnosed during 2014 to 2019 (till September) were collected from the files of the Oral Pathology Department, M.M. College of Dental Sciences \& Research, Mullana (Ambala). The data were collected according to the variables; age, gender and site.

\section{Results}

Out of the total 71 cases of odontogenic cysts, most prevalent odontogenic cysts were found to be radicular cysts $(n=42, \%=59.1 \%)$, followed by dentigerous cysts $(n=17, \%=23.9 \%)$ and odontogenic keratocyst $(n=12, \%=16.9 \%)$. Among the odontogenic tumors out of 49 cases reported, the most prevalent was ameloblastoma $(\mathrm{n}=28, \%=57.1 \%)$ followed by, ameloblastic fibroma $(\mathrm{n}=06, \%=12.2 \%)$, odontoma $(\mathrm{n}=05, \%=10.2 \%)$, adenomatoid odontogenic tumor $(\mathrm{n}=03, \%=6.1 \%)$, peripheral odontogenic fibroma $(\mathrm{n}=02$, $\%=4.08 \%)$, ameloblastic carcinoma $(n=02, \%=4.08 \%)$, odontogenic fibroma ( $\mathrm{n}=02, \%=4.08 \%)$ and odontogenic myxofibroma $(\mathrm{n}=01, \%=2.04 \%)$. The anterior and posterior portion of the body of mandible was the most common site for both odontogenic cysts and tumors. The age group for odontogenic cysts ranged from 07 to 72 years of age, whereas for the odontogenic cysts the range was 10 to 75 years of age. The male to female ratio (M:F) for the odontogenic cysts was 1:1.2, whereas for the odontogenic tumors it was found to be 1:1.3.

\section{Discussion}

Odontogenic cyst and tumors account for less than 2-3\% of all oral and maxillofacial lesions. ${ }^{1}$ More than $95 \%$ of all odontogenic tumors are reported in large series are benign and around $75 \%$ are represented by odontomas, ameloblastomas and myxomas. ${ }^{5}$ In the present study, Out of the total 71 cases of odontogenic cysts, most prevalent odontogenic cysts were found to be radicular cysts $(n=42, \%=59.1 \%)$, followed by dentigerous cysts $(n=17, \%=23.9 \%)$ and odontogenic keratocyst $(n=12, \%=16.9 \%)$ which is in accordance to other studies in various countries. ${ }^{4,6-9}$ This high incidence of radicular cysts may be due to the precarious oral conditions of the population studied and the lack of public awareness to prevent oral infectious diseases. ${ }^{4}$ Among the odontogenic tumors out of 49 cases reported, the most prevalent was ameloblastoma $(n=28$, $\%=57.1 \%)$ followed by ameloblastic fibroma $(n=06$, $\%=12.2 \%)$, odontoma $(n=05, \%=10.2 \%)$, adenomatoid odontogenic tumor $(\mathrm{n}=03, \%=6.1 \%)$, peripheral odontogenic fibroma $(\mathrm{n}=02, \%=4.08 \%)$, ameloblastic carcinoma $(\mathrm{n}=02, \%=4.08 \%)$, odontogenic fibroma $(\mathrm{n}=02, \%=4.08 \%)$ and odontogenic myxofibroma $(\mathrm{n}=01$, $\%=2.04 \%$ ). Similarly, studies from Nigeria, China, Tanzania, and SriLanka show a higher prevalence of ameloblastoma. ${ }^{10-14}$ Ameloblastoma accounts for $60.3 \%$ of all odontogenic tumors in Indian population, with a mean age of presentation of 30.2 years. ${ }^{15}$ As studies on the incidence of ameloblastomas are rare but at the molecular level, it was observed that the transforming growth factor- $\beta$ (TGF- $\beta$ )/SMAD signaling pathway is commonly activated in ameloblastomas, adenomatoid odontogenic tumor, and calcifying cystic odontogenic tumors. Meanwhile, the TGF- $\beta /$ SMAD immuno reaction is significantly reduced in ameloblastomas in comparison to AOT's and calcifying cystic odontogenic tumors. These changes may lead to the more aggressive biological behavior of ameloblastomas through increased cell proliferation and reduced apoptosis and differentiation. ${ }^{16}$ In the present study, the anterior and posterior portion of the body of mandible was the most common site for both odontogenic cysts and tumors similar to the studies reported by Nunez-Urrutia et $\mathrm{al}^{7}{ }^{7}$ Avelar et $\mathrm{al}^{6}$ and Meningaud et $\mathrm{al}^{17}$ whereas many previous studies have reported maxilla ${ }^{18-20}$ was the anatomic site most often affected by odontogenic cysts but there is no definitive explanation in the literature related to site variations. ${ }^{21}$

The age group for odontogenic cysts ranged from 07 to 72 years of age, whereas for the odontogenic tumors the range was 10 to 75 years of age. The male to female ratio for the odontogenic cysts was 1:1.2 with a female predilection. Similar results have been reported in Brazilian population. ${ }^{22}$ On the contr4ary, male predominance was found in other studies ${ }^{22-26}$ whereas for the odontogenic tumors it was found to be having 
more female predilection with the ratio of 1:1.3.

\section{Conclusion}

The prevalence of odontogenic cysts was similar to that reported in the literature, with incidence of radicular cysts seen most frequently. In case of odontogenic tumors the findings vary to the reported literature with ameloblastoma being more commonly reported.

Ethical Clearance: Since it was a retrospective study, there was no need for the ethical clearance from the committee.

\section{Source of Funding: Self}

\section{Conflict of Interest: Nil}

\section{Reference}

1. Imran A, Jayanthi $\mathrm{P}$, Tanveer $\mathrm{S}$, Gobu SC. Classification of odontogenic cysts and tumors - Antecedents. J Oral MaxillofacPathol 2016;20(2):269-71.

2. Chi AC, Neville BW. Odontogenic cysts and tumors. SurgPatholClin 2011; 4(4):1027-91.

3. Holla VA, Chatra L, Shenai P, Rao PK, Veena K, Prabhu RV. Bilateral inflammatory cysts of the jaw: report of an unusual case. 2012;42(2):105-9.

4. Da Sliva LP, Gonnzaga AK, Severo ML, Barros CC, de Medeiros AM, de Souza LB et al. Epidemiological study of odontogenic and nonodontogenic cysts in children and adolescents of a Brazilian population. Med Oral Patol Oral Cir Buccal 2018;23(1):e49-53.

5. Philipsen HP, Reichart PA. Classification of odontogenic tumor. A historical review. J Oral Pathol Med 2006;35:525-9.

6. Avelar RL, Antunes AA, Carvalho RWF, Bezerra PGC, Neto PJO, Andrade ESS. Odontogenic cysts: a clinicopathological study of 507 cases. J Oral Sci. 2009;51:581-586.

7. Urrutia SN, Figueiredo R, Gay-Escoda C. Retrospective clinicopathological study of 418 odontogenic cysts. Med Oral Patol Oral Cir Bucal. 2010;15:e767-e773.

8. Selvamani M, Donoghue M, Basandi PS. Analysis of 153 cases of odontogenic cysts in a South Indian sample population: a retrospective study over a decade. Braz Oral Res. 2012;26:330-334.

9. Ramchandra P, Maligi P, Raghuveer HP. A cumulative analysis of odontogenic cysts from major dental institutions of Bangalore city: a study of 252 cases. J Oral MaxillofacPathol. 2011;15:15.

10. Odukoya O. Odontogenic tumors: Analysis of 289 Nigerian cases. J Oral Pathol Med. 1995;24:454.

11. Arobita JT, Ogunbiyi JO, Obiechina AE. Odontogenic tumours: A 15-year review from Ibadan, Nigeria. Br J Oral Maxillofac Surg. 1997;35:363.

12. Lu Y, Xuan M, Takata $T$, et al. Odontogenic tumors: a demographic study of 759 cases in a Chinese population. Oral Surg Oral Med Oral Pathol. 1998;86:707.

13. Simon EN, Merkx MA, Vuhahula E, Ngassapa D, Stoelinga PJ. A 4-year prospective study on epidemiology and clinic pathological presentation of odontogenic tumors in Tanzania. Oral Surg Oral Med Oral Pathol Oral RadiolEndod. 2005;99:598602.

14. Okada H, Yamamoto H, Tilakaratne WM. Odontogenic tumors in Sri Lanka: analysisof 226 cases. J Oral Maxillofac Surg. 2007;65(5):875882.

15. Krishnapillai R, Angadi PV. A clinical, radiographic, and histologic review of 73 cases of ameloblastoma in an Indian population. Quintessence Int. 2010;41:e90-100.

16. Karathanasi V, Tosios KI, Nikitakis NG, et al. TGF-beta1, Smad-2/-3, Smad-1/-5/-8, and Smad-4 signaling factors are expressed in ameloblastomas, adenomatoid odontogenic tumors, and calcifying cystic odontogenic tumors: an immunohistochemical study. J Oral Pathol Med. 2013;42:415-423.

17. Meningaud JP, Oprean N, Pitak-Arnnop P, Bertrand JC. Odontogenic cysts: a clinical study of 695 cases. J oral sci 2006;48:59-62.

18. De Souza LB, Gordón-Núñez MA, Nonaka CF, de Medeiros MC, Torres TF, Emiliano GB. Odontogenic cysts: demographic profile in a Brazilian population over a 38 -year period. Med Oral Patol Oral Cir Bucal. 2010;15:e583-e590

19. Grossmann SM, Machado VC, Xavier GM, Moura MD, Gomez RS, Aguiar MC. Demo-graphic profile of odontogenic and selected nonodontogenic cysts in a Brazilian population. Oral Surg Oral Med Oral 
Pathol Oral RadiolEndod. 2007;104:e35-e41.

20. Prockt AP, Schebela CR, Maito FD, Sant'AnaFilho M, Rados PV. Odontogenic cysts: analysis of 680 cases in Brazil. Head Neck Pathol. 2008;2:150156.

21. Ackigoz A, Uzun-Bulut E, Ozden B, Gunduz K. Prevalence and distribution of odontogenic and nonodontogenic cysts in a Turkish population. Med oral patol oral cir buccal 2012;17(1):e108-e115.

22. Batista de Souza L, Gordón-Núñez MA, Weege Nonaka CF, Costa de Medeiros M, Fernandes Torres T, Guedes Emiliano GB. Odontogenic cysts: demographic profile in a Brazilian population over a 38-year period. Med Oral Patol Oral Cir Bucal. 2010;15:e583-e590.
23. Jones AV, Craig GT, Franklin CD. Range and demographics of odontogenic cysts diagnosed in a UK population over a 30-year period. J Oral Pathol Med. 2006;35:500-507.

24. Tortorici S, Amodio E, Massenti MF, Buzzanca, Burruano F, Vitale F. Prevalence and distribution of odontogenic cyst in Sicily: 1986-2005. J Oral Sci. 2008;50:15-18.

25. Mosqueda-Taylor A, Irigoyen-Camacho ME, DiazFranco MA, Torres-Tejero MA. Odontogenic cysts. Analysis of 856 cases. Med Oral. 2002;7:89-96.

26. Ledesma-Montes $\mathrm{C}$, Hernández-Guerrero JC, Garcés-Ortíz M. Clinico-pathologic study of odontogenic cysts in a Mexican sample population. Arch Med Res. 2000;31:373-376. 